\title{
Convenient Synthesis of Some Novel N3-Substituted 3, 4-Dihydropyrimidin-2(1H)-one Derivatives
}

\author{
R. A. SHASTRI
}

P.G. Department of Chemistry, S.B.E.S. College of Science, Aurangabad-431001, Maharashtra, India

shastriranjana@yahoo.com

Received 9 May 2018 / Accepted 1 June 2018

\begin{abstract}
A simple and convenient method for the synthesis of $N 3$-substituted 3,4-dihydropyrimidinones has been achieved by the condensation of 3,4-dihydropyrimidinones with benzoyl chloride in pyridine. The advantages of this method are excellent yields, short reaction time, no-side reaction, operational simplicity and ease in experimental procedure. The key intermediate 3,4dihydropyrimidin-2(1H)-ones have been synthesized by condensation of $\beta$-ketoester, aromatic aldehydes and $N$-methyl urea using PTSA.
\end{abstract}

Keywords: Dihydropyrimidinones, PTSA, Benzoyl chloride, Pyridine

\section{Introduction}

3,4-Dihydropyrimidin-2-(1H)-one derivatives have received considerable attention within recent years due to their attractive pharmacological properties ${ }^{1}$. In the past decades, dihydropyrimidinones scaffold have emerged as integral backbones of several calcium channel blockers, antihypertensive agents, $\alpha$-1a-antagonists and neuropeptide Y(NPY) antagonists $^{2}$. Dihydropyrimidinone derivatives are found as core units in many marine alkaloids (batzelladine and carambine), which have been found to be potent to HIV-gp-120 CD4 inhibitors ${ }^{3}$.

As a consequence, the synthesis of dihydropyrimidinone derivatives bearing diverse substitution patterns has attracted significant attention since its discovery by the Italian chemist Pietro Biginelli ${ }^{4}$. In recent years several methods for the synthesis of DHPMs have been developed to improve and modify this reaction by means of microwave irradiation ${ }^{5}$, ultrasound irradiation ${ }^{6}$, promoted by $\mathrm{PPh}^{7}$, Lewis acids such as boric acid $^{8}$, $\mathrm{KA} 1\left(\mathrm{SO}_{4}\right)_{2} .12 \mathrm{H}_{2} \mathrm{O}$ supported on silica gel ${ }^{9,10}, \mathrm{Sr}(\mathrm{OTf})_{2}$, Indium (III)halides ${ }^{11,12}, \mathrm{Bi}\left(\mathrm{NO}_{3}\right)_{3}$, -tungstophosphoric acid $^{13,14}, \mathrm{Cu}(\mathrm{OTf})_{2}$, sulfonated $\beta$-cyclodextrine ${ }^{15}$, sulfatedtungstate ${ }^{16}$, lanthanum chloride ${ }^{17}$ and Chloroacetic $\operatorname{acid}^{18}$. It is still valuable to synthesise new derivatives of DHPMs, due to its importance in organic and medicinal chemistry. 
Literature survey reveals that, no reports are available for $N 3$-benzoyl substitution in dihydropyrimidinone nucleus. The present attempt is to substitute $N_{3}-\mathrm{H}$ by benzoyl group in the molecular framework of DHPM to obtain new molecule with the intention that this group may display intensified bioactivity. In continuation of our earlier work, carried to develop convenient synthetic protocol for the synthesis of bioactive heterocycle ${ }^{19}$, herein we report the synthesis of new DHPM derivatives.

\section{Experimental}

Chemicals and solvents required were from Merck and SD fine Meck. All melting points were determined in open capillaries in paraffin bath and are uncorrected. The progress of the reactions was monitored by thin layer chromatography. The products were characterized by their spectral data. IR spectra were recorded on Perkin -Elmer FTIR spectrophotometer in $\mathrm{KBr}$ disc. ${ }^{1} \mathrm{H}$ NMR spectra were recorded on Bruker advance at $400 \mathrm{MHz}$ in $\mathrm{CDCl}_{3}$ as solvent and chemical shift values are recorded in ppm relative to tetramethylsilane as an internal slandered. Mass spectra were recorded on micro mass VG 7070H mass spectrometer.

General procedure for the synthesis of ethyl-1,2,3,4-tetrahydro-1,6-dimethyl-2-oxo4-phenylpyrimidine-5-carboxylate (4a-n)

A mixture of aldehyde $(1 \mathrm{mmol})$, ethyl acetoacetate $(2 \mathrm{mmol})$ and $\mathrm{N}$-methyl urea $(2 \mathrm{mmol})$ were heated under reflux by using PTSA $(0.25$ mole $\%)$ in ethanol $(10 \mathrm{~mL})$ for 120 mins. The progress of the reaction was monitored by thin layer chromatography on Merck plates (silica gel 60F-254) using solvent $N$-hexane -ethyl acetate (9:1) and after completion of reaction, mixture was allowed to cool and poured on ice cold water. The solid was filtered, washed with water and crystallized by aqueous ethanol and characterized by spectroscopic techniques.

General procedure for the synthesis of ethyl 3- benzoyl-1,2,3,4-tetrahydrohydro1,6-dimethyl-2-oxo- phenylpyrimidine-5 carboxylate (5a-n)

A mixture of substituted dihydropyrimidones $(1 \mathrm{mmol})$ in dry pyridine $(3 \mathrm{~mL})$, benzoyl chloride $(4 \mathrm{mmole})$ was heated at $160{ }^{\circ} \mathrm{C}$ for $3 \mathrm{~h}$ and left at room temperature for $24 \mathrm{~h}$. The reaction mixture was poured on ice cold water and, pyridine was neutralized by hydrochloric acid. Excess benzoyl chloride was hydrolysed by $5 \% \mathrm{NaOH}$, obtained solid / semisolid compound was recrystallized from aqueous ethanol and characterized by IR, NMR and Mass

Ethyl-1,2,3,4-tetrahydro-1,6-dimethyl-2-oxo-4-(4-flurophenyl)pyrimidine-5carboxylate $(\mathbf{4 d})$

IR $\left(\mathrm{KBr}, v\left(\mathrm{~cm}^{-1}\right)\right): 1226(\mathrm{CO}), 1687(\mathrm{C}=\mathrm{O}), 1709(\mathrm{C}=\mathrm{O}), 2981(\mathrm{C}-\mathrm{H}$ aliph $), 3109$ (C-H aroma), $3225(\mathrm{~N}-\mathrm{H}), \mathrm{cm}^{-1} .{ }^{1} \mathrm{H}$ NMR $(\mathrm{CDCl} 3): \delta(\mathrm{ppm}): 1.18\left(\mathrm{t}, 3 \mathrm{H}, J=7.2 \mathrm{~Hz},-\mathrm{COCH}_{2} \mathrm{CH}_{3}\right), 2.51$ (s, $\left.3 \mathrm{H}, \mathrm{CH}_{3}\right), 3.20\left(\mathrm{~s}, 3 \mathrm{H}, \mathrm{N}-\mathrm{CH}_{3}\right), 4.10\left(\mathrm{q}, 2 \mathrm{H}, \mathrm{J}=7.2 \mathrm{~Hz},-\mathrm{COCH}_{2} \mathrm{CH}_{3}\right), 5.36(\mathrm{~d}, 1 \mathrm{H}, \mathrm{CH}), 6.39$ (s, 1H, NH), 6.93-7.27 (m,4H, Ar-H) Es-MI. $293\left(\mathrm{M}^{+}\right)$100\%. $\mathrm{C}_{15} \mathrm{H}_{18} \mathrm{FN}_{2} \mathrm{O}_{3}$ calculated: C: $61.42 \%, \mathrm{H}: 6.19 \%, \mathrm{~N}: 9.55 \%$ found: C: $61 \%, \mathrm{H}: 6.10 \%, \mathrm{~N}: 9.45 \%$.

\section{Ethyl-3-benzoyl-1,2,3,4-tetrahydrohydro-1,6dimethyl-2-oxo-4(4-flurophenyl)} pyrimidine-5-carboxylate $(\mathbf{5 d})$

IR $\left(\mathrm{KBr}, v\left(\mathrm{~cm}^{-1}\right)\right): 1096 \mathrm{~cm}^{-1}$ 1272(CO), 1674(C=O), 1703(C=O), 2977(C-H aliph), 3063(C-H aroma), ${ }^{1} \mathrm{H}$ NMR $\left(\mathrm{CDCl}_{3}\right): \delta(\mathrm{ppm}): 1.28\left(\mathrm{t}, 3 \mathrm{H}, J=7.0 \mathrm{~Hz},-\mathrm{CH}_{3}\right), 2.63(\mathrm{~s}, 3 \mathrm{H}$, $\left.\mathrm{CH}_{3}\right), 3.16\left(\mathrm{~s}, 3 \mathrm{H}, \mathrm{CH}_{3}\right), 4.25\left(\mathrm{q}, 2 \mathrm{H}, J=7.0 \mathrm{~Hz}, \mathrm{CH}_{2}\right), 6.40(\mathrm{~s}, 1 \mathrm{H}, \mathrm{CH}), 6.97-7.52(\mathrm{~m}, 9 \mathrm{H}$, Ar-H) Es-MI. 397( $\left.\mathrm{M}^{+}\right) 100 \% \mathrm{C}_{22} \mathrm{H}_{22} \mathrm{FN}_{2} \mathrm{O}_{4}$ calculated C: $66.49 \%, \mathrm{H}: 5.58 \%, \mathrm{~N}: 7.05 \%$ found: C: $66.48 \%, \mathrm{H}: 5.55 \%, \mathrm{~N}: 6.99 \%$. 
Ethyl-3- benzoyl-1,2,3,4-tetrahydrohydro-1,6dimethyl -2-oxo-4 (4-chloro phenyl)pyrimidine -5 -carboxylate $(\mathbf{5 f})$

IR (KBr,v $\left.\left(\mathrm{cm}^{-1}\right)\right)$ : $1092 \mathrm{~cm}^{-1}$ 1272(CO), 1676(C=O), 1699(C=O), 2978(C-H aliph),. 3064(C-H aroma), ${ }^{1} \mathrm{H}$ NMR $(\mathrm{CDCl} 3): \delta(\mathrm{ppm}): 1.29\left(\mathrm{t}, 3 \mathrm{H}, J=7.0 \mathrm{~Hz}, \mathrm{CH}_{3}\right), 2.62(\mathrm{~s}, 3 \mathrm{H}$, $\left.\mathrm{CH}_{3}\right), 3.14\left(\mathrm{~s}, 3 \mathrm{H}, \mathrm{CH}_{3}\right), 4.24\left(\mathrm{q}, 2 \mathrm{H}, J=7.0 \mathrm{~Hz}, \mathrm{CH}_{2}\right), 6.40(\mathrm{~s}, 1 \mathrm{H}, \mathrm{CH}), 7.26-7.55(\mathrm{~m}, 9 \mathrm{H}$, Ar-H). Es-MI. $413\left(\mathrm{M}^{+}\right) 100 \% \mathrm{C}_{22} \mathrm{H}_{22} \mathrm{ClN}_{2} \mathrm{O}_{4}$ calculated: C: $63.84 \%, \mathrm{H}: 5 . .36 \%, \mathrm{~N}: 6.77 \%$ found: C: $63.78 \%, \mathrm{H}: 5.25 \%, \mathrm{~N}: 6.45 \%$.

Methyl-3- benzoyl -1,2,3,4-tetrahydrohydro-1,6-dimethyl-2-oxo-4 (4-chlorophenyl)pyrimidine -5 -carboxylate $(5 \boldsymbol{k})$

IR $\left(\mathrm{KBr}, v\left(\mathrm{~cm}^{-1}\right)\right): 1092 \mathrm{~cm}^{-1}$ 1272(CO), 1676(C=O), 1699(C=O), 2978(C-H aliph),. 3064(C-H aroma), ${ }^{1} \mathrm{H} \mathrm{NMR}\left(\mathrm{CDCl}_{3}\right): \delta(\mathrm{ppm}): 1.89\left(\mathrm{~s}, 3 \mathrm{H}, \mathrm{CH}_{3}\right), 2.62\left(\mathrm{~s}, 3 \mathrm{H}, \mathrm{CH}_{3}\right), 3.14\left(\mathrm{~s}, 3 \mathrm{H}, \mathrm{CH}_{3}\right)$, 6.40(s, 1H, CH), 7.26-7. 55 (m, 9H, Ar-H) Es-MI. $\left.399\left(\mathrm{M}^{+}\right) 100 \%\right) \mathrm{C}_{22} \mathrm{H}_{22} \mathrm{ClN}_{2} \mathrm{O}_{4}$ calculated: C: $63.84 \%, \mathrm{H}: 5 . .36 \%, \mathrm{~N}: 6.77 \%$ found: C: $63.50 \%, \mathrm{H}: 5.00 \%, \mathrm{~N}: 6.45 \%$.

\section{Results and Discussion}

In continuation of our research to develop methods for various transformations ${ }^{20-23}$, we herein report protocol for the synthesis of new dihydropyrimidinone derivatives. The key starting compounds DHPM (4a-n) required for this conversion are synthesized by the reported procedure in literature ${ }^{19}$, by treating $N$-methyl urea, substituted aromatic aldehyde and ethyl/methyl acetoacetate in the presence of PTSA in ethanol, the results are summarized in Table 1 and Scheme 1.

Synthesized dihydropyrimidones (4a-n) on reacting with benzoyl chloride in the presence of pyridine as solvent, yielded (5a-n). For the optimization of reaction conditions, various trial reactions were conducted on model reaction. To optimize the temperature in the model reactions, we have carried out a study with ethyl-1,2,3,4 tetrahydro1,6-dimethyl-2-oxo-4-phenylpyrimidine-5-carboxylate using benzoyl chloride at various temperatures in pyridine. Table 2 clearly demonstrate that $160{ }^{\circ} \mathrm{C}$ is an effective temperature in terms of reaction time and yields. The higher temperature required for the reaction indicates, that the substitution at $\mathrm{N}-3$ of dihydropyrimidones by bulkier group is more difficult.

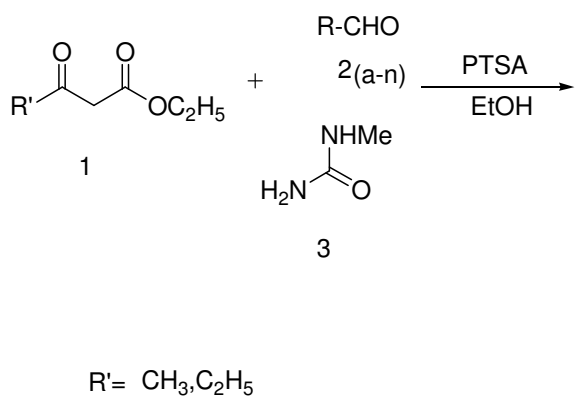

Scheme 1
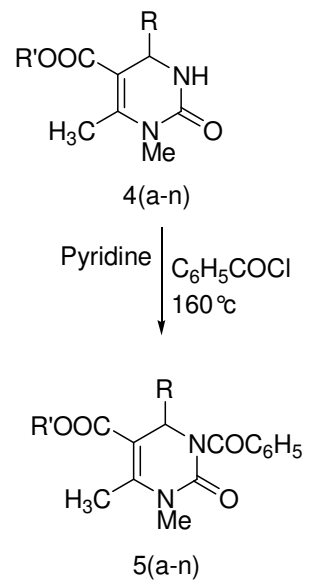
T able 1. Synthesis of ethyl 4-(phenyl)-1, 2, 3, 4-tetrahydro-1,6dimethyl -2-oxopyrimidine5-carboxylate (4a-n)

\begin{tabular}{ccccc}
\hline Entry & $\mathrm{R}$ & $\mathrm{R}$ & Yield\% & M.P. ${ }^{\circ} \mathrm{C}$ \\
\hline $\mathbf{4 a}$ & $\mathrm{C}_{6} \mathrm{H}_{5}$ & $\mathrm{Et}$ & 90 & $172-3^{\mathrm{a}}$ \\
$\mathbf{4 b}$ & $3(\mathrm{Br})-\mathrm{C}_{6} \mathrm{H}_{4}$ & $\mathrm{Et}$ & 93 & $112-4$ \\
$\mathbf{4 c}$ & $3\left(\mathrm{NO}_{2}\right)-\mathrm{C}_{6} \mathrm{H}_{4}$ & $\mathrm{Et}$ & 92 & $132-3$ \\
$\mathbf{4 d}$ & $4(\mathrm{~F})-\mathrm{C}_{6} \mathrm{H}_{4}$ & $\mathrm{Et}$ & 95 & $123-4$ \\
$\mathbf{4 e}$ & $3(\mathrm{Cl})-\mathrm{C}_{9} \mathrm{H}_{5} \mathrm{~N}$ & $\mathrm{Et}$ & 92 & $>300$ \\
$\mathbf{4 f}$ & $4(\mathrm{Cl})-\mathrm{C}_{6} \mathrm{H}_{4}$ & $\mathrm{Et}$ & 96 & 124 \\
$\mathbf{4 g}$ & $3,4,5\left(\mathrm{OC} \mathrm{CH}_{3}\right)-\mathrm{C}_{6} \mathrm{H}_{2}$ & $\mathrm{Et}$ & 86 & 146 \\
$\mathbf{4 h}$ & $4(\mathrm{OH})-\mathrm{C}_{6} \mathrm{H}_{4}$ & $\mathrm{Et}$ & 84 & $178-9$ \\
$\mathbf{4 i}$ & $4(\mathrm{OCH})-\mathrm{C}_{6} \mathrm{H}_{4}$ & $\mathrm{Et}$ & 89 & $132-4$ \\
$\mathbf{4 j}$ & $\mathrm{C}_{6} \mathrm{H}_{5}$ & $\mathrm{Me}$ & 85 & $188-90$ \\
$\mathbf{4 k}$ & $4(\mathrm{Cl})-\mathrm{C}_{6} \mathrm{H}_{4}$ & $\mathrm{Me}$ & 86 & $137-8$ \\
$\mathbf{4 l}$ & $3\left(\mathrm{NO} \mathrm{O}_{2}\right)-\mathrm{C}_{6} \mathrm{H}_{4}$ & $\mathrm{Me}$ & 88 & $203-4$ \\
$\mathbf{4 m}$ & $2(\mathrm{Cl})-\mathrm{C}_{6} \mathrm{H}_{4}$ & $\mathrm{Et}$ & 91 & $140-2$ \\
$\mathbf{4 n}$ & $\mathrm{C}_{4} \mathrm{H}_{3} \mathrm{O}$ & $\mathrm{Et}$ & 95 & $132-4$ \\
\hline
\end{tabular}

Reaction conditions: benzaldehyde (1 mmole), $N$-methyl urea $(2$ mmole $)$, methyl/ethyl acetoacetate (2 mmole), ethanol $(10 \mathrm{~mL})$, reflux time $(2 \mathrm{~h}) .{ }^{a}$ Synthesized compound is compared with those reported in literature ${ }^{24}$ and found to be identical.

Table 2. Effect of temperature on yields of the model reaction

\begin{tabular}{ccc}
\hline Entry & Temperature, $0{ }^{\circ} \mathrm{C}$ & Yield $\%$ \\
\hline 1 & 100 & Trace quantity \\
2 & 120 & $20-25$ \\
3 & 140 & $50-55$ \\
4 & 160 & $80-85$ \\
\hline
\end{tabular}

Reaction conditions: DHPM 4 a (1mmole),benzoyl chloride $(4$ mmole).pyridine $(3 \mathrm{~mL})$,time $(3 \mathrm{~h})$

Furthermore, we have focussed our attention on the effect of benzoyl chloride concentration on model reaction. The reaction proceeds at 2 mmol concentration of benzoyl chloride at effective temperature with very low yield, however 3 mmol gave moderate yield but the concentration of $4 \mathrm{mmol}$ gave higher yield, further increase in concentration did not progress the yield's In order to drive reaction to completion, however, generally an excess of one of the component has to be employed. The reaction didn't proceed in the absence of pyridine. The results are summarized in Table 3.

Table 3. Optimization of benzoyl chloride concentration on yields of the model reaction

\begin{tabular}{ccc}
\hline Entry & Temperature, $0{ }^{\circ} \mathrm{C}$ & Yield $\%$ \\
\hline 1 & 1 & Trace quantity \\
2 & 2 & $20-25$ \\
3 & 3 & $55-60$ \\
4 & 4 & $85-90$ \\
\hline
\end{tabular}

Reaction conditions: DTPM4a $(1 \mathrm{mmol})$, benzoyl chloride $(1-4 \mathrm{mmol})$.pyridine $(3 \mathrm{~mL})$, time $(3 \mathrm{~h})$, temperature $160^{\circ} \mathrm{C}$

With all above optimised conditions (Scheme 2) in hand we then generalized this approach to various dihydropyrimidinones (5a-n), the results are summarized in Table 4. 


$$
\mathrm{R}^{\prime}=\mathrm{CH}_{3}, \mathrm{C}_{2} \mathrm{H}_{5}
$$

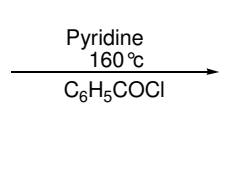

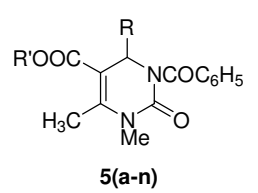

\section{Scheme 2}

Table 4. Synthesis of ethyl 3-benzoyl-1,2,3,4-tetrahydrohydro-1,6-dimethyl-2-oxophenylpyrimidine -5-carboxylate (5a-n)

\begin{tabular}{ccccc}
\hline Entry & $\mathrm{R}$ & $\mathrm{R}^{\prime}$ & Yield\% & M.P. ${ }^{\circ} \mathrm{C}$ \\
\hline $\mathbf{5 a}$ & $\mathrm{C}_{6} \mathrm{H}_{5}$ & $\mathrm{Et}$ & 90 & $127-30$ \\
$\mathbf{5 b}$ & $3(\mathrm{Br})-\mathrm{C}_{6} \mathrm{H}_{4}$ & $\mathrm{Et}$ & 93 & $90-92$ \\
$\mathbf{5 c}$ & $3\left(\mathrm{NO}_{2}\right)-\mathrm{C}_{6} \mathrm{H}_{4}$ & $\mathrm{Et}$ & 92 & $166-67$ \\
$\mathbf{5 d}$ & $4(\mathrm{~F})-\mathrm{C}_{6} \mathrm{H}_{4}$ & $\mathrm{Et}$ & 95 & $148-50$ \\
$\mathbf{5 e}$ & $3(\mathrm{Cl})-\mathrm{C}_{9} \mathrm{H}_{5} \mathrm{~N}$ & $\mathrm{Et}$ & 92 & $>300$ \\
$\mathbf{5 f}$ & $4(\mathrm{Cl})-\mathrm{C}_{6} \mathrm{H}_{4}$ & $\mathrm{Et}$ & 96 & $164-66$ \\
$\mathbf{5 g}$ & $3,4,5\left(\mathrm{OCH}{ }_{3}\right)-\mathrm{C}_{6} \mathrm{H}_{2}$ & $\mathrm{Et}$ & 86 & $120-21$ \\
$\mathbf{5 h}$ & $4(\mathrm{OH})-\mathrm{C}_{6} \mathrm{H}_{4}$ & $\mathrm{Et}$ & 84 & $196-98$ \\
$\mathbf{5 i}$ & $\left.4(\mathrm{OCH})_{3}\right)-\mathrm{C}_{6} \mathrm{H}_{4}$ & $\mathrm{Et}$ & 85 & $124-26$ \\
$\mathbf{5 j}$ & $\mathrm{C}_{6} \mathrm{H}_{5}$ & $\mathrm{Me}$ & 85 & $124-26$ \\
$\mathbf{5 k}$ & $4(\mathrm{Cl})-\mathrm{C}_{6} \mathrm{H}_{4}$ & $\mathrm{Me}$ & 86 & $140-42$ \\
$\mathbf{5 l}$ & $3\left(\mathrm{NO}_{2}\right)-\mathrm{C}_{6} \mathrm{H}_{4}$ & $\mathrm{Me}$ & 88 & $94-96$ \\
$\mathbf{5 m}$ & $2(\mathrm{Cl})-\mathrm{C}_{6} \mathrm{H}_{4}$ & $\mathrm{Et}$ & - & - \\
$\mathbf{5 n}$ & $\mathrm{C}_{4} \mathrm{H}_{3} \mathrm{O}$ & $\mathrm{Et}$ & - & - \\
\hline
\end{tabular}

Reaction conditions: DHPMs (1 mmole), benzoyl chloride $\left(4\right.$ mmole).pyridine $(3 \mathrm{~mL})$, reflux temperature $160{ }^{\circ} \mathrm{C}$, time $(3 h)$

A structural evaluation of the new DHPM derivatives and intermediate synthesized in this study was performed using spectroscopic techniques. The IR spectra of $\mathbf{4 d}$ showed normal stretching absorption band, indicating the existence of the $\mathrm{NH}\left(3225 \mathrm{~cm}^{-1}\right)$, ester carbonyl $\left(1709 \mathrm{~cm}^{-1}\right)$ and carbonyl $\left(1687 \mathrm{~cm}^{-1}\right)$ moieties. ${ }^{1} \mathrm{H}$ NMR showed the presence of $\mathrm{N}-\mathrm{CH}_{3}$ and $\mathrm{NH}$ proton as singlet at $\delta 3.20,6.39$ respectively, aromatic region showed the presence of four protons in the region 6.93-7.27. The ESI-MS of compound revealed the existence of their molecular ion peak, which is in accordance with the structure.

The IR and ${ }^{1} \mathrm{H}$ NMR spectra of $\mathbf{5 d}, \mathbf{5}$ and $\mathbf{5 k}$ showed the absence of N-H band and its aromatic region showed the presence of nine protons. The ESI-MS of compound revealed the existence of their molecular ion peak, which is in accordance with the structure at $397,413.399$ respectively.

We observed the influence of substitution pattern on the yield of reaction (5a-n). The presence of substituent on the phenyl ring of DHPMs has influence on the formation of product.

Phenyl group substituted at Meta and Para position by electron donating and electron withdrawing groups were well tolerated providing good yield of the desired product. Whereas phenyl group substituted at ortho position for which reaction didn't proceed, it may be due to the steric hindrance. 


\section{Conclusions}

In conclusion, some novel compounds of methyl/ ethyl-3-benzoyl-1,2,3,4- tetrahydrohydro1,6-dimethyl-2-oxo-phenyl pyrimidine-5-carboxylates have been synthesized. An important feature of this synthesis is that electron releasing or withdrawing groups at Meta and Para position on the aromatic ring of DPHMs gave high yields. The fascinating scope of this synthetic strategy is its excellent yield, short reaction time, no-side reaction and operational simplicity and ease product isolation procedure, hence this method is helpful for synthesis of $\mathrm{N}$-3-benzoyl-3,4-dihydropyrimidin-2(1H)-one scaffold.

\section{Acknowledgement}

Author thanks to SAIF, Chandigarh for providing IR and $\mathrm{H}^{1}$ NMR spectral facilities. Author thanks to SAIF, Lucknow for providing Mass spectra.

\section{References}

1. Kappe O C, Acc Chem Res., 2000, 33(12), 879-888; DOI:10.1021/ar000048h

2. Rovnyak G C, Kimball S D, Beyer B, C Gabriella C, John D D, Jack G, Anders H, Mary M, James P, McCarthy, Rongan Z and Suzanne M, J Med Chem., 1995, 38(1), 119-129; DOI:10.1021/jm00001a017

3. Patil A D, Kumar N V, Kokke W C, Mark F, Bean J, Freyer, Charles, DeBrosse, Shing Mai, Alemseged Truneh, Brad Carte, Ann L Breen, Robert PHertzberg, Randall K Johnson, John W Westley and Barbara C M Potts, J Org Chem., 1995, 60(5), 1182-1188; DOI:10.1021/jo00110a021

4. Biginelli P, Gazz Chim Ital., 1893, 23, 360-413.

5. Banik B K, Reddy B, Reddy AT, Datta A and Mukhopadhyay C, Tetrahedron Lett., 2007, 48(41), 7392-7394; DOI:10.1016/j.tetlet.2007.08.007

6. L Li J T, Han J F, Yang J H and Li T S, Ultrason Sonochem., 2003, 10(3), 119-122; DOI:10.1016/S1350-4177(03)00092-0

7. Debache A, Amimour M, Belfaitah A, Rhouati S and Carboni B A, Tetrahedron Lett., 2008, 49(49), 6119-6121; DOI:10.1016/j.tetlet.2008.08.016

8. Tu Sh, Fang F, Miao F, Jiang H, Feng Y, Shi D and Wang X, Tetrahedron Lett., 2003, 44(32), 6153-6155; DOI:10.1016/S0040-4039(03)01466-7

9. Azizian J, Mohammadi A A, Karirni A R and Mohammadizadeh M R, Appl Catal A Gen., 2006, 300(1), 85-88; DOI:10.1016/j.apcata.2005.11.001

10. Su W, Li J, Zheng Zh and Shen Y, Tetrahedron Lett., 2005, 46(36), 6037-6040; DOI:10.1016/j.tetlet.2005.07.021

11. Fu N Y, Yuan Y F, Pang M L, Wang I T and Peppe C, J Organomet Chem., 2003, 672(1-2), 52-57; DOI:10.1016/S0022-328X(03)00139-6

12. Ming L, Si G W, Rong W L, Feng L I and Zhang Y H, Mol Catal A Chem., 2006, 258, 133-138; DOI:10.1016/j.molcata.2006.05.028

13. Heravi M M, Derikvand F and Bamoharram F A, Mol Catal A Chem., 2005, 242(1-2), 173-175; DOI:10.1016/j.molcata.2005.08.009

14. Paraskar A S, Dewkar G K and Sudalai A, Tetrahedron Lett., 2003, 44(16), 33053308; DOI:10.1016/S0040-4039(03)00619-1

15. Asghari S, Tajbakhsh M, Kenari B J and Khaksar S, Chin Chem Lett., 2011, 22(2),127-130; DOI:10.1016/j.cclet.2010.09.030

16. Salim S D and Akamanchi K G, Catal Commun., 2011, 12(12), 1153-1156;

DOI:10.1016/j.catcom.2011.02.018 
17. Jun L, Yinjuan B, Zhenjun W, Bingqin $\mathrm{Y}$ and Huairang M, Tetrahedron Lett., 2000,41(47), 9075-9078; DOI:10.1016/S0040-4039(00)01645-2

18. Yang Y, Di L, Chunsheng L and Genxiang L, Bioorg Med Chem Lett., 2007, 17(12), 3508-3510; DOI:10.1016/j.bmcl.2006.12.068

19. Shastri R A and Joshi P P, Chem Sci Trans., 2018, 7(1), 2278-3458; DOI:10.7598/cst2018

20. Shastri R A and Goswami D D, Indian J Heterocycl Chem., 2001, 11(1), 51-54.

21. Shastri R A, Pedgaonkar S V, Selukar S S and Jadhav S B, Indian J Chem Soc., 2008, 85, 574-576.

22. Shastri R A and Varudkar J S, Indian J Chem., 2009, 48B, 1156-1160.

23. Shastri R A, Indian J Chem., 2013, 52B, 160-63.

24. Khajesamani H, Pouramini B, Tavakolinejad E, Kermany and Khabazzadeh H, J Sci Islamic Republic Iran., 2014, 25(4), 323-327. 